\title{
O JOGO LÚDICO NA ESCOLA DE ENSINO BÁSICO ${ }^{1}$
}

Recebido em: 27/04/2018

Aceito em: 26/09/2018

\author{
Angela Barcellos Café ${ }^{2}$ \\ Universidade Federal de Goiás \\ Goiânia - GO - Brasil
}

RESUMO: Os discursos e interesses por pesquisas e estudos que envolvem a o lúdico, o jogo, o brinquedo e a brincadeira na educação estão crescendo em qualidade e quantidade nas pesquisas acadêmicas, entretanto, não necessariamente correspondem à um cenário de ações lúdicas dentro das escolas. Por mais que se aponte a importância das atividades lúdicas na formação de qualquer pessoa, em qualquer idade, é visível a manutenção de uma prática na escola endurecida, rígida, repetitiva $\mathrm{e}$ descontextualizada, cercadas por violências de todos os tipos. O lugar do jogo e da brincadeira quase não acontece, nem nos momentos "permitidos", como as atividades festivas, nas datas comemorativas. Este estudo vem contribuir com contextualizações históricas em torno do lúdico e do que o envolve, com vistas a superar a desvalorização de suas manifestações associadas a atividades sérias, ampliando suas possibilidades de atuação na escola, por meio de elementos fundantes do jogo e de suas características, como espaço propício à esta manifestação. Esse objetivo tem como pano de fundo a crença de que um ambiente lúdico é favorável à um clima de partilha e aprendizagem. Este ensaio, teve como base observações etnográficas realizadas em escolas, em sua maioria de ensino público, nos níveis fundamental e médio, durante mais de 30 anos de experiência e que serviram de base aos questionamentos e reflexões constantes no texto. Ao mesmo tempo a pesquisa participante se fez presente por fazer várias vezes, em percursos de idas e vindas entre planejamento, prática de novas ações e reflexões com as análises em busca de respostas, ainda que provisórias. A revisão bibliográfica orientada neste percurso aponta múltiplas áreas do conhecimento: Filosofia; Antropologia; Sociologia; Psicologia; Pedagogia; Estudos do Lazer. As considerações finais apontam para uma convergência nas possibilidades de atuação lúdica na escola, utilizando o jogo, brinquedo ou brincadeira em qualquer das áreas do conhecimento, considerando as características de: estratégia, desenvolvimento e conhecimento, para um ensino/aprendizagem mais significativos.

PALAVRAS CHAVE: Jogos e Brinquedos. Cultura. Escola. Atividades de Lazer.

THE LUDIC GAME IN THE HIGH SCHOOL

\footnotetext{
1 Artigo premiado no III Congresso Brasileiro de Estudos do Lazer/XVI Seminário "O Lazer em Debate", realizado em Campo Grande/MS em 2018.

2 Doutora em Artes pela UnB; mestre em estudos do Lazer (Unicamp); especialista em metodologia do ensino superior (UFG); graduada em Educação Física (UEG); Contadora de histórias. Pesquisadora de Cultura Popular, ludicidade; formação em educação escolar, elaboração de material didático.
} 
ABSTRACT: Speeches and interests on topics surrounding ludic, game, toy itself and the play in education are increasing in quality and in quantity in academic researches, however not necessarily relating to ludic actions inside schools. Despite pointing out the importance of ludic activities on one's formation, regardless of age, the practice of a hard, strict, repetitive and decontextualized system, surrounded of all kinds of violence, continues to be enforced in school environments. Games and fun activities almost never happen, as they do not usually have a place, not even on "permitted" moments, such as festive activities and celebration dates. This study contributes with the historical contextualization around ludic and its surroundings, aiming to surpass the devaluation of its manifestations associated to serious activities, expanding the possibility of implementation at school, through fundamental elements of game and its characteristics, such as a propitious space for this manifestation. This objective is based on the belief that a ludic environment is favorable to a sharing and learning atmosphere. This essay has as foundation the ethnographic observations that took place in schools, mostly in public education, from primary to high school, for over 30 years of experience, in which the constant inquiries and reflections seen in the text are based. At the same time, such research has reemerged several times, along the way, in between planning, practice of new actions and reflections with analysis that has been made, looking for answers, even if interims. Bibliographic review orientated throughout this path point out multiples knowledge areas: Philosophy, Anthropology, Sociology, Psychology, Pedagogy, and Leisure Studies. Final considerations indicate a convergence on ludic actuation possibilities in school, using the game, toys or plays in any of those knowledge areas, considering the following: strategy, development and knowledge, to a more significant education/learning.

KEYWORDS: Play and Playthings. Culture. School. Leisure Activities.

\title{
Abrindo Diálogos
}

\author{
"Os filósofos contemporâneos, \\ aqueles formadores de opinião, \\ passam a proclamar que o próximo \\ milênio será o da ludicidade"! \\ Airton Negrine
}

O jogo de que tratamos aqui, é o jogo lúdico, considerando outras esferas possíveis de compreensão de “jogo”, que não pertencem ao foco deste estudo, a exemplo de envolvimento com competições, jogos interpessoais estudados no psicodrama ou psicanálise, ou ainda outros enfoques possíveis, que não estão interessados no entendimento da manifestação lúdica. A forma primogênita de jogo, que 
acompanha o ser humano em sua existência, observada nos feitos e registros da humanidade encontrados ao longo da história, sobretudo encontrando obras de arte de culturas diferentes retratando os mesmos jogos, chamaram minha atenção. Mais especificamente, os interesses se voltaram aos significados que a vivência desses jogos traz historicamente relacionadas à educação, no contexto da escola atual. Tudo aquilo que pode contribuir com a mudança do atual cenário da escola de ensino básico, desde o aspecto físico até a base curricular, passando pelo sistema como se estrutura, faz parte do meu interesse e objetivo maior. Quem sabe contribuir para aos poucos substituir a violência do cotidiano escolar por um clima de partilha, curiosidade, cooperação, um espaço de convivência e aprendizagem, prazeroso e agradável antes de tudo. Em meu percurso profissional persigo uma educação para a autonomia, em que o jovem esteja preparado para ter iniciativa, resolvendo os problemas que aparecerem com criatividade, amenizando as injustiças sociais que historicamente construíram o país, atuando como sujeitos livres e participantes da vida social. Não é fácil educar para o desconhecido... Surgem inseguranças, possibilidades de não alcançar o planejado, frustrações. Mas, é também isso tudo que impulsiona o professor para as reflexões, pesquisando entendimentos de seu fazer. O medo paralisa e a ação pode transformar!

Essa busca do conhecimento é também uma investigação de si mesmo, o autoconhecimento, é base para a construção da liberdade individual e coletiva. Os estudos e as práticas me ensinaram que no brincar são reveladas as posições que se tem do mundo, o sujeito se assume em suas condições únicas, suas reações revelam seus valores e sua moral. Por meio da brincadeira verificamos o entendimento das relações com o mundo, entre as coisas e as pessoas. Trago essa experiência em mim, com a oportunidade de sempre misturar brincadeiras no cotidiano. Venho de uma família em 
que a brincadeira tem um valor cotidiano, intrínseco ao nosso modo de vida, garantido pela frase tantas vezes repetidas de meu pai: "temos que cultivar o bom humor", no mínimo para aprender a ser flexível.

A descoberta deste estudo se fez por duas vias: na vivência em sala de aula como professora, em mais de trinta anos na educação básica e ensino superior, na formação de professores, nas áreas de Educação Física e atualmente nas Artes Cênicas; e, no encontro com autores que entravam em consonância com minhas observações empíricas, vivenciadas na escola, na valorização da ludicidade e reclamação das atitudes de violência. Como professora, compartilhava com os alunos momentos de muita descontração, quando por exemplo: dizia que era aula livre e juntava toda a turma em uma única ação, "fazendo uma correnteza em círculo, para soltar o corpo e flutuar"3. Estava garantida a aprendizagem da flutuação, mas aos olhos de alguns tradicionalistas da educação... a aula era uma bagunça. Se por um lado, a escola oferecia espaços propícios para os estudantes vivenciarem manifestações lúdicas, por ser uma escola de Aplicação da Universidade Federal de Goiás - UFG, por outro lado os cursos de formação de professores no Estado e Municípios me mostravam uma realidade bastante adversa. As práticas em sua maioria se limitavam a cópias de conteúdos na lousa (quadro giz; quadro negro), nem sempre escritos pelo(a) professor(a), que muitas vezes pedia à um(a) aluno(a) com letra bonita ${ }^{4}$, para encher o quadro. A apatia de crianças e adolescentes dos vários níveis escolares que fingiam aprender, enquanto pretensos professores que fingiam ensinar foi a observação mais repetida em minhas andanças na

\footnotetext{
${ }^{3}$ Aula de Educação Física - natação - para ensino fundamental, anos iniciais no CEPAE - Centro de Ensino e Pesquisa Aplicados à Educação (antigo Colégio de Aplicação) em 1994; escola que aceitava e abria espaços diversos para manifestações lúdicas, onde tive a oportunidade de estudar e lecionar por mais de dez anos.

${ }^{4}$ Me impressionava o fato de raramente ouvir críticas de estudantes mais interessados ou esclarecidos, no sentido de que não era este o papel de uma estudante, muito menos de um docente, que visivelmente boicotava seu próprio trabalho.
} 
formação de professor. Quanto maior o ano escolar, maior também o descaso dos professores, acompanhado do desinteresse total dos alunos, que respondem ao que lhes é oferecido. Esta situação pertence à maioria das escolas visitadas ou relatadas por professores de escolas públicas e muitas vezes também de escolas privadas, em cursos de formação de professores, no Estado de Goiás e cursos de contadores de histórias espalhados por quase todos os estados brasileiros.

Se por um lado, algumas escolas públicas permitem que a sala de professores vire um centro comercial, inclusive retirando os professores de sala de aula na chegada de novos produtos, por outro lado, a escola privada chega a proibir trabalhos em grupo, em nome do conteúdo do rendimento, do que os pais vão pensar... isso aqui não é brincadeira!

Em um Brasil de múltiplas realidades, infelizmente vejo predominar a cópia e a obediência na escola, com todas as consequências advindas desse tipo de educação. A paisagem mais comum encontrada e/ou relatada, referente ao ambiente escolar, aponta para violência e bullying em crescimento.

Nesse sentido, acreditando no poder contagiante do riso, um ambiente em que a brincadeira é aceita como natural e usufruída com interesse, poderia pôr fim à um ambiente agressivo, cheio de desconfianças, suspeitas e hostilidades. As brincadeiras têm o poder de despertar potencialidades no desenvolvimento humano, pois requer sentimento de partilha e de respeito às normas combinadas. Investigações e experiências nesse sentido já mostraram a capacidade lúdica de transformação de comunidades inteiras, verificados em escolas e ONGs, cujo compromisso é social, podendo ser 
verificados nos estudos de diversos autores ${ }^{5}$. Este primeiro grupo de autores que me influenciou na medida em que os conhecia, participam aqui de forma conjunta, por fazerem parte de quem sou, por meio dos conhecimentos que me formaram e sustentam meu pensamento e minha prática.

Para este estudo trago algumas áreas envolvidas nos conceitos, definições e/ou noções de: lúdico, jogo, brinquedo e brincadeira, provocada pela percepção da falta de alegria no ambiente escolar. A investigação procura entender, como e por que, a sociedade desvaloriza as ações lúdicas, impedindo sua manifestação em ambientes de aprendizagem, contrapondo a atividades sérias que nada desenvolvem.

A primeira atenção se volta para a fragmentação das sociedades modernas, explicadas na Filosofia, e no conceito de cultura pela Antropologia. A compreensão fragmentada de sujeito e de sociedade, provocam aumento de preconceitos e falta de tolerância com aquilo que é diferente. Na Sociologia percebemos o acesso desigual, às oportunidades de aprendizagem, com influência de tantos fatores que chegamos a questionar a possibilidade de alguma transformação. Porém, é na Psicologia e na Pedagogia que encontramos respostas mais pontuais, com ações individuais e coletivas na direção de superar o cotidiano feio e triste de uma escola em um ambiente acolhedor, lúdico e propício a trocas constantes de aprendizagens.

Iniciamos com a percepção de Huizinga (1971), que denuncia, nos tempos modernos, uma supervalorização do trabalho produtivo em detrimento do Lazer, em que aos poucos foi sendo construída a vinculação da seriedade ao trabalho. Para o autor, o lúdico foi desaparecendo do cotidiano na vida urbana, sobretudo, na compreensão de seu aspecto como manifestação inerente ao ser humano. Compreendido dessa forma,

\footnotetext{
${ }^{5}$ Estudos e experiências que envolvem aspectos e/ou atividades lúdicas podem ser encontrados em: Rousseau; Froebel; Montessory; Claparéde; Pestalozzy; Dewey; Decroly; Cousinet; Makarenko; Brougère; Wallon; Vigotsky; Piaget; Chateau.
} 
precisa de espaço para se manifestar e podem ter no jogo, no brinquedo ou na brincadeira um ambiente favorável à sua manifestação. Isso passa pelas noções de que o lúdico é um "estado interno do sujeito" (LUCKESI, 2002).

Essa compreensão afasta o entendimento do lúdico enquanto substantivo, tornando sem sentido algumas falas presentes nas escolas, do tipo: "precisamos de mais lúdico"; "vamos trazer o lúdico para nossa escola"! "Nossa escola tem o lúdico, está no planejamento". Ao mesmo tempo nos deparamos com salas de aula equipadas com brinquedos, mas que tem 'dia e hora da semana para brincar', mostrando que nem a presença física de um brinquedo pode garantir uma manifestação lúdica.

Analisar o lúdico historicamente nos ajuda perceber quais são os espaços propícios à sua manifestação, nos tempos atuais, sendo essa a primeira parte de deste estudo. Mais que um conceito ou uma definição fechada as noções que perpassam o aspecto lúdico podem nos levar a compreensões diferentes em cada contexto ou tempo histórico. Durante essa discussão apresento obras de artes de outros tempos, cujas brincadeiras ainda perduram, com a intensão de ampliar o repertório dos professores e mostrar que a maioria delas são brincadas há séculos.

Num segundo momento, trago esclarecimentos sobre conceitos e definições de jogo, brinquedo e brincadeira, por entender que estas vivências provocam a ludicidade que ao se manifestar contagia o ambiente. Com essa discussão aponto seis elementos que constituem o jogo, ou seja, características presentes em qualquer jogo que podem orientar a criação de novas estratégias de ensino, independente da área de atuação do professor, permitindo a manifestação lúdica no ambiente escolar. Ao entender a importância da vivência lúdica na formação de qualquer pessoa o professor passa a 
desenvolvê-la na escola sem medo de cobranças por seriedade, pois brincadeira é coisa séria!

\section{O Direito ao Lúdico}

[...] discutem os etnólogos se é o arco de caça e guerra ou o arco musical a forma primogênita do arco. A solução do debate não é coisa que agora nos importe. O simples fato de que pode ser discutido demonstra que, seja ou não musical o arco originário, aparece entre os instrumentos mais primitivos. $\mathrm{E}$ isto basta. Porque isso nos revela que o primitivo não sentia menos como necessidade o proporcionar-se certos estados prazerosos que o satisfazer suas necessidades mínimas para não morrer; portanto, que desde o início o conceito de 'necessidade humana' inclui indiferentemente o objetivamente necessário e o supérfluo (ORTEGA e GASSET).

A manifestação lúdica sempre esteve presente nas atitudes e significações do fazer humano e, sempre foi considerada tão necessária quanto o trabalho para sua existência. $\mathrm{O}$ homem sempre se alimentou do útil e do supérfluo ao mesmo tempo, com a preocupação da sobrevivência, ou da diversão, ou melhor, sem estabelecer valores diferentes entre um e outro. Nesse sentido, pode-se entender que a ludicidade também é parte natural da cultura, vivenciada em momentos indistintos, desde as sociedades mais primitivas e/ou tradicionais.

Ao analisar o elemento lúdico em sua existência na história, Huizinga (1971) percebe que esse sempre fez parte da vida do homem até o início da modernidade, quando, em razão da mudança no modo de produção houve supervalorização do trabalho produtivo em detrimento do lazer. Outros estudos e pesquisas apontam a mesma direção, constatando uma diminuição da importância dos jogos e festas, em contraste com o crescimento e valorização do trabalho, a partir dos séculos XVII e XVIII.

Precisamos entender porque nossa sociedade foi diminuindo o valor do brincar. 
Por que atualmente se considera a ludicidade, que envolve a brincadeira, como coisa de criança? Ou seja, porque o brincar é tratado como coisa infantil? Só à criança é permitida a manifestação da ludicidade naturalmente aliada ao brinquedo? Adulto não brinca? É o que dita o senso comum. É o que parece gritar a sociedade em que vivemos. Então, por que as escolas impedem também as crianças limitando a brincadeira em nome da seriedade da aprendizagem? O que o brincar e a brincadeira tem a ver com o lúdico? Todas as sociedades pensam sobre o lúdico da mesma maneira? Buscando entender qual o sentido do lúdico na vida das pessoas, ao longo da história, percebemos que antes das revoluções industriais não existia o conhecimento da infância, produzidos pela Psicologia e Pedagogia, que pertencem aos séculos XIX e XX.

Phillipe Ariés, em seu livro, A História Social da Criança e da Família (1982), mostra que, até o final do século XVII, as crianças e adolescentes eram praticamente ignorados pela sociedade. A duração da infância reduzia-se ao seu período mais frágil, em que a criança era tratada como uma "coisinha engraçadinha, apenas enquanto o filhote do homem que ainda não conseguia bastar-se. Mal essa criança conseguia algum desembaraço físico, era logo misturada aos adultos e partilhavam de seus trabalhos e jogos" (1982, p. 36).

De criancinha pequena, ela se transformava imediatamente em um jovem adulto, sem passar pelas etapas da infância e juventude, que se tornaram aspectos essenciais das sociedades de hoje. De maneira que não havia distinção ou diferenciação entre a criança, o adolescente, o adulto ou qualquer outra fase conhecida ou nomeada, como conhecemos hoje. Isso tudo pertence ao desenvolvimento da modernidade e ao seu equivalente mundo do consumo (quanto mais fragmentado, melhor). 
Estudos ${ }^{6}$ apontam que este pensamento foi paulatinamente tomando conta da sociedade moderna e firmando a ideia de que brincadeira é coisa de criança em razão de que a brincadeira não produz algo lucrativo, assim como a criança também é um ser ainda incapaz de produzir. No entanto, essa mesma sociedade continua entendendo a criança como um adulto em potencial, pois a maioria dos brinquedos não deixa de ser uma imitação do futuro mundo adulto: bonecas e panelinhas para as meninas; carrinhos e ferramentas para os meninos. Crítica apontada por vários desses autores nos estudos da cultura da infância.

Diferenças no modo de vida entre as sociedades tradicionais e modernas podem ser percebidas, quando analisamos algumas obras de Arte de épocas diferentes. Como exemplo, seleciono uma obra do século XVI, a fim de mostrar não só que as brincadeiras atravessaram séculos e ainda perduram, mas também a importância da Arte como documento histórico da humanidade. No cotidiano das pessoas nelas retratado, a ludicidade, por ser parte característica da brincadeira, permeia as várias atividades humanas, demonstrando não haver distinção nem separação dos campos culturais, ou espaços determinados de atuação, como nas sociedades atuais, que exigem tempos e espaços adequados.

\footnotetext{
${ }^{6}$ Nelson C. Marcellino; Roger Caillois; Walter Benjamin; Paulo Salles de Oliveira; Heloisa Brums; e outros.
} 


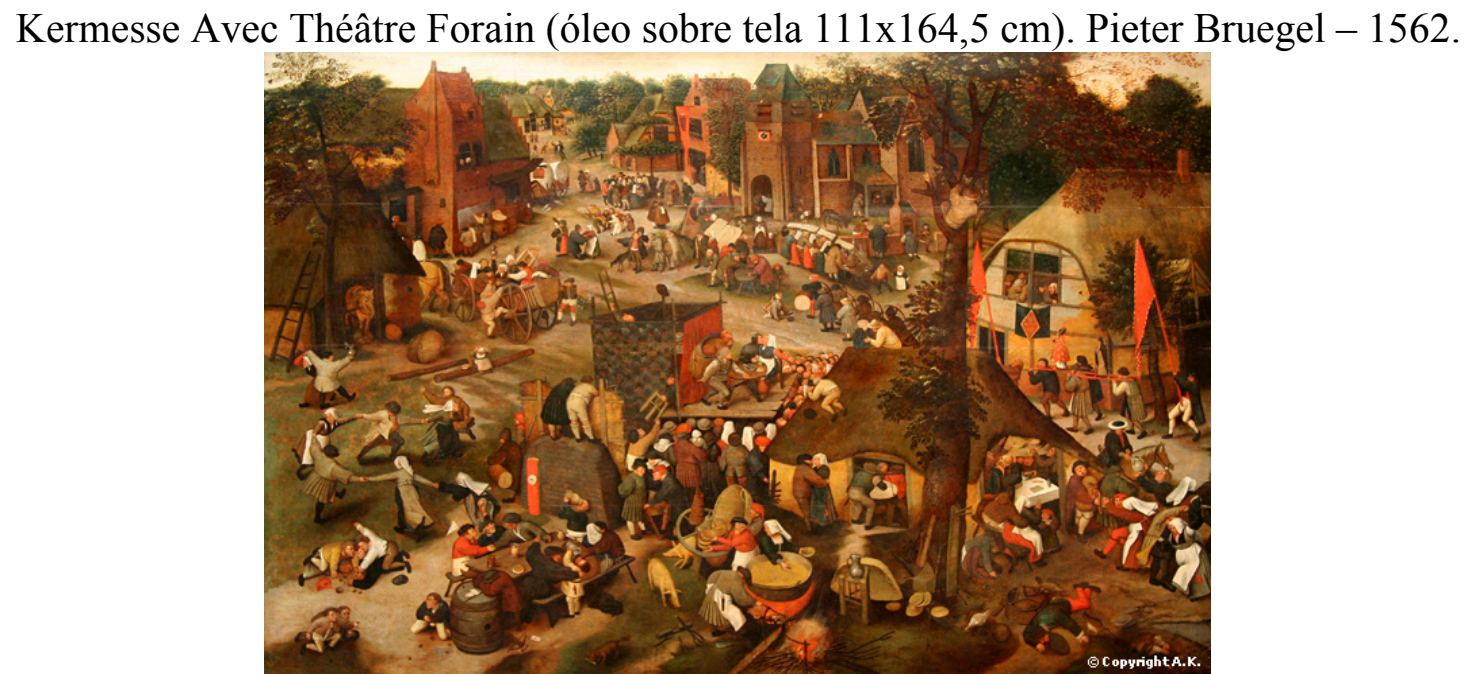
Fonte: http://www.artinthepicture.com/paintings/Pieter_Brueghel_the_Younger/The-
Kermesse-of-St-George/ Acesso em: 11 mar. 2010.

Um dos exemplos mais ricos, já estudado e analisado sob diversos aspectos, por teóricos diferentes, é a obra de Peter Brüegel: Brincadeira de rapazes (1563). Duas características dessa obra podem ser observadas, trazendo contribuições e possibilidades de análise. A primeira tratase da descrição do quadro, em que aparece uma enorme quantidade de homens e mulheres em miniaturas (podendo ser entendidos como crianças ou não), todos envolvidos com jogos, brinquedos e brincadeiras, reafirmando a posição de Ariés, segundo a qual a criança não fazia parte de um contexto próprio, mas pertencia ao mundo como um adulto qualquer. A distinção entre adultos e crianças, retratada nas obras dessa época, era apenas no tamanho dos personagens, podendo ser observado que as crianças conservam traços dos adultos como, por exemplo, proporção do corpo e fisionomia. 
Brincadeira de Rapazes (Peter Brüeghel, O Velho, 1563; óleo sobre madeira - Museu de Viena).

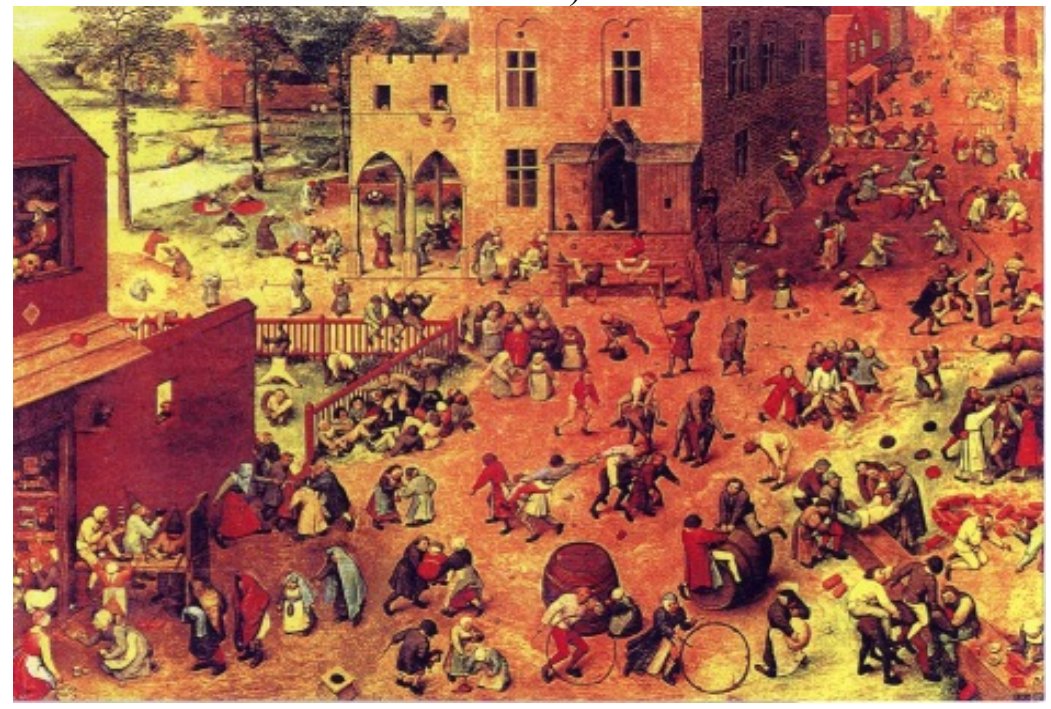

Fonte: (BROWN, 1978, p.12)

Outra característica interessante é perceber que os mais de setenta exemplos de brincadeiras que aparecem nessa obra, como: pião, cata-vento, cambalhota, roda, pula carniça, gangorra, quebra pote, perna de pau, cavalinho, arco, cabra-cega e outras, foram e ainda são vividos por crianças de todo o mundo, de várias culturas diferentes e em épocas distintas, o que nos mostra que essas brincadeiras atravessaram milênios perpetuando-se, ainda que modificadas. Por outro lado, se compararmos com os brinquedos e brincadeiras de outras culturas como a oriental, africana e indígena, vamos encontrar muitas semelhanças e repetições dos mesmos brinquedos: cabo de guerra, aro, cavalinho, roda, cambalhota, espadinha, pique esconde, pipa e outros.

Seguindo a ideia de observar pinturas e/ou imagens de brinquedos e brincadeiras em culturas distintas pode-se identificar as semelhanças, entre as várias atividades, por exemplo, neste quadro de cultura japonesa: pipa, bambolê, pião, corda, carrinho de boneca, perna de pau, e outros; e deixo o incentivo para o leitor buscar mais imagens nas culturas indígenas e africanas, a fim de constatar analogias possíveis. 


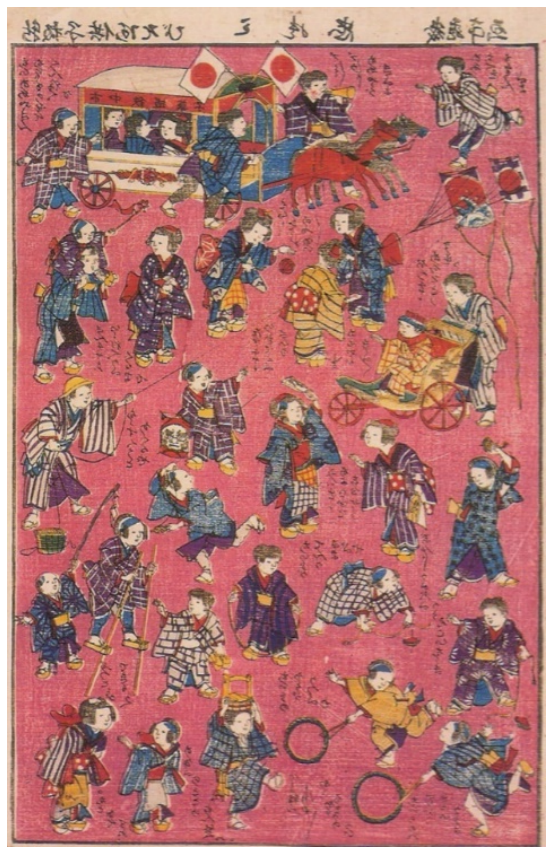

Fonte: (MICKLETHWAIT, 1997, p.11)

Outros exemplos de obras de Arte, anteriores ao século XVI, reafirmam e comprovam a existência de brincadeiras e jogos conhecidos da infância de hoje, cuja origem perde-se no tempo, como podemos perceber na pintura em mármore:

As jogadas de ossinhos (pinturas sobre mármore, proveniente de Herculano - Museu Nacional de Nápoles)

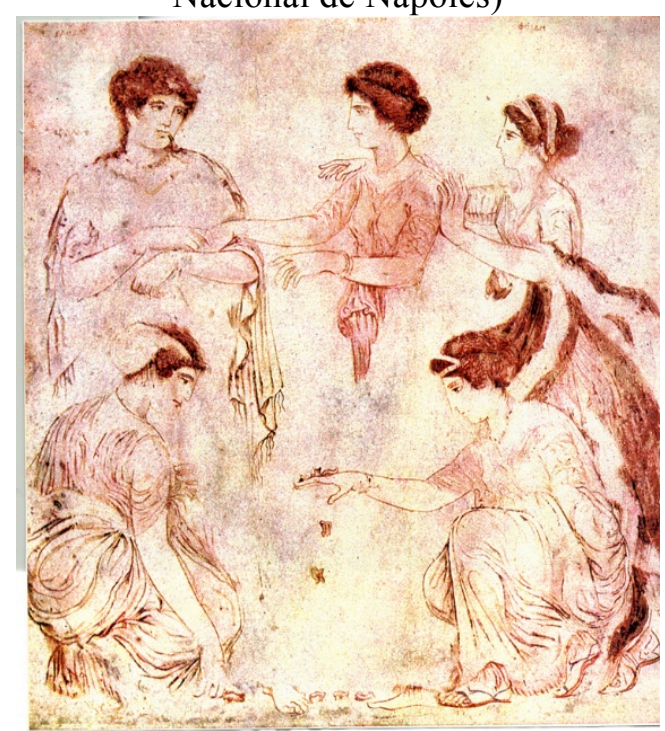

Fonte: (SKIRA, 1953, p.104).

Essa brincadeira é também conhecida por 'baliza' ou '5 marias', jogada ainda hoje na região nordeste do Brasil, com ossinhos de frango, em Minas Gerais com saquinhos de 
areia ou sementes e em Goiás e outras regiões com pedrinhas. Diversas obras de Arte de tempos e espaços diferentes possibilitam a identificação de outros jogos e sua possível origem, além de conhecer brincadeiras de outras culturas, ou de outras épocas, que não se perpetuaram nas práticas infantis de hoje e que podem ser recuperadas.

A importância dessa recuperação está não só no conhecimento histórico das brincadeiras, mas na possibilidade de realizar brincadeiras coletivas, contrapondo-se aos brinquedos atuais, que já vêm prontos e, em relação aos quais, a criança mais observa do que brinca. Uma outra característica dos brinquedos atuais consiste na sua tendência à individualização. Diante de um brinquedo digital, por exemplo, ninguém tem vontade ou necessidade de conversar, trocar experiências, vivenciar comportamentalmente uma atividade, criar, viver uma fantasia... Dar asas à imaginação. Antes que a máquina se torne a maior companheira do ser humano do futuro próximo, há muito que se aprender com as brincadeiras e experiências de outras épocas. Pelo desenvolvimento das várias capacidades de linguagem estimuladas por essa vivência. E sobretudo pela vivência coletiva que constrói e edifica o sujeito individualmente.

Os exemplos das brincadeiras, mostram que certos traços culturais preservam sua essência e, simultaneamente, transformam-se no decorrer dos tempos e no contexto de cada sociedade. As obras de Arte são registros de extrema riqueza para o entendimento e recuperação de diferenças culturais de outras épocas, embora pouco explorados com este fim.

À medida que as sociedades se tornaram complexas e o modo de produção capitalista dividiu a sociedade em classes sociais, a cultura se compartimentou. Hoje, os campos culturais tornaram-se isolados. No campo científico, houve uma fragmentação das ciências e, no interior de cada área científica, várias especializações que exigem 
profissionais competentes para cada saber. Ao mesmo tempo, a vida se compartimentou exigindo hora e momento próprio para cada atividade humana. Nos centros urbanos, com o advento dos meios de comunicação social, há certa uniformidade das atividades culturais, todas elas dentro de um perfil estabelecido, de produtos prontos que empobrecem a criatividade.

O processo de urbanização e industrialização em que se vive hoje separa nitidamente os campos do trabalho e do lazer. A ruptura lazer/trabalho tem significado o desaparecimento do lúdico, uma vez que a sociedade só valoriza a utilidade, ou seja, o produto que dá lucro. E só o trabalho pode produzir algo útil, lucrativo. Essa realidade é explicada (significada) pelas teorias que mostram como o trabalhador, no sistema capitalista, vende sua força de trabalho e se aliena, por não se reconhecer autor do seu trabalho, mas também por se encontrar impedido da possibilidade do prazer, de criar e de ser $^{7}$. A exemplo disso observa-se que a criança, o velho e o deficiente físico, na sociedade atual, são de certa forma excluídos, por serem considerados incapazes de produzir algo que tenha utilidade.

A essa ideia contrapõe-se a análise de Leontiev (1988), para quem: “o brinquedo é caracterizado pelo fato de seu alvo residir no próprio processo e não no resultado da ação. [...] no jogo adulto, quando a vitória, mais que uma simples participação, torna-se motivo interior, o jogo deixa de ser brincadeira" (p.28).

O jogo não pode ser considerado uma atividade produtiva, pois seu objetivo não está em seu resultado, mas na própria ação. No entanto, tem se transformado em mercadoria, em trabalho, com a utilização de profissionais treinados para performances prontas. Pacotes em colônias de férias e academias, ou brinquedos com marcas

\footnotetext{
${ }^{7}$ Para o aprofundamento da teoria de Karl Marx sobre a mercadoria, consultar o primeiro capítulo: O Capital. Col. Os Pensadores, vol. I, Rio de Janeiro, Paz e Terra, 1974.
} 
determinadas parecem ser condição para conquista da felicidade das crianças de hoje. Assim como as viagens e colônias de férias para idosos, apenas para aqueles que conseguiram construir certa condição financeira.

A lógica de produtividade social ao vincular o lúdico à criança, faixa etária caracterizada pela improdutividade, o considera algo não sério. Dessa forma, o brinquedo é permitido na escola infantil, mas com tempo marcado e diferenciado das atividades sérias, próprias da escola. A criança entra na escola para aprender como se tornar adulto, nessa lógica, deve-se distinguir brincadeira e responsabilidade. Do mesmo modo, os adultos raramente reconhecem a naturalidade de uma brincadeira, sobretudo em ambiente de trabalho e, dificilmente conseguem perceber este fato. Atualmente, esse discurso tem se modificado, entretanto, sem resultados significativos, pois a reivindicação se manifesta no sentido de trazer o lúdico para a escola, enquanto o contexto atual aponta para uma necessidade de abrir espaços, na escola, para a vivência do prazer e da ludicidade da criança e do adolescente, seja em jogos e brincadeiras ou em outras atividades.

Em seus estudos Huizinga (1971) reconhece a ludicidade como pertencendo à natureza não só humana, pois ela se manifestava antes mesmo de existir cultura, que é puramente da condição do homem. $\mathrm{O}$ autor afirma que a ludicidade já está presente até mesmo nos animais irracionais e, quem é dono de cães, por exemplo, pode facilmente concordar e identificar quando os cachorros estão brincando. Este brinquedo é o próprio jogo reconhecido pelo ser humano como atividade lúdica, "os animais brincam tais como os homens" (idem, p.03). Portanto, podemos afirmar pelo autor que a ludicidade, por inseparável do jogo ou do brincar, é inerente ao ser humano sendo, inclusive, anterior a sua cultura.

Por outro lado, a liberdade permitida ou provocada pelo brinquedo contrapõe-se a 
uma visão de uma educação tradicional, que acredita na aprendizagem pela repetição, infelizmente ainda presente em muitas das escolas, sobretudo nas atividades de sala de aula. A visão de que o aluno é alguém que não sabe e tem muito a aprender com um professor que sabe tudo, colocando o professor como dono de uma verdade, um modelo a ser seguido e repetido, faz parte de uma educação alienada, onde o aluno não precisa aprender a pensar por si só. Essa prática, que permaneceu por muitos anos no cotidiano da escola, é questionada desde os meados do século XX, por desconsiderar que o aluno, ao chegar à escola, traz consigo uma experiência que o diferencia das outras crianças, mas que, ao mesmo tempo, as aproxima, quando lhes é dada a oportunidade da troca de experiências.

Assim, a Educação para o século XXI assume a necessidade de formar um ser que conheça e entenda seu potencial individual/universal, para a sua atuação em cada contexto social e político. A dificuldade dos profissionais de Educação, em pensar e lidar com as diferenças, não só físicas, mas também culturais apresentadas pelos alunos é histórica. Hoje se reconhece a necessidade de valorizar e trabalhar os jogos e brincadeiras, como heranças da cultura local, regional e universal, estabelecendo relações possíveis entre esses níveis, preservando e aprendendo a aceitar e conhecer as diferenças culturais entre as pessoas.

Para Bruner (1963), “Os indivíduos diferem por causa das variações na constituição genética, e por causa de suas experiências singulares no decorrer da vida". Assim, na expressão de Clayde Kluckhohn e Henry A. Murray:

Cada homem é em certos aspectos, como todos os outros homens; como alguns outros homens; como nenhum outro homem (apud BRUNER, 1963, p. 220).

Três aspectos constituem o ser humano: sua universalidade, sua regionalidade e 
sua individualidade. Universalmente, todos estão em busca de ser e viver felizes, de uma ou de muitas maneiras diferentes, ou seja, social e individualmente. Todo ser humano, nesse mundo, precisa de carinho e de respeito, sem exceção. Existem aspectos universais ao ser humano, outros são características regionais de uma dada cultura, além das características absolutamente individuais, sendo esse o mistério da singularidade

\section{humana.}

Certamente que ninguém nunca desejou a sordidez, a feiura ou a falta de sentido. Se FREUD esteve certo ao afirmar que somos todos vitalmente fascinados pela busca do prazer (princípio do prazer), ou bem antes de FREUD esteve certo ARISTÓTELES ao ponderar que a vida humana é uma caminhada constante à procura da felicidade, ninguém pode ter planejado e desejado construir a própria infelicidade do atual ambiente, que caracteriza a tecnologia científica. No entanto todos fomos contribuindo para a construção de um ambiente feio, frequentemente sórdido, e para a instalação de um modo de viver vazio e desorientado (MORAIS, 1988, p. 158).

Os jogos populares e outras brincadeiras apresentam com clareza os três níveis da realidade humana. Em um mesmo jogo, percebemos todas essas características, pois ele é primeiramente universal, conhecido por todos, e brincado durante séculos ou milênios (como vimos no jogo de baliza). Divulgado e (re)inventado em vários locais, sofre, entretanto, interferências culturais de cada região; pode e é interpretado individualmente, de acordo com as experiências pessoais e socioculturais de quem está brincando, sendo comum a alteração de regras $^{8}$ para cada realidade.

O importante é não perdermos a perspectiva da vivência da manifestação lúdica, que como nos mostra Ortega \& Gasset é não só contemporânea da pessoa, mas intrínseca a esta. Outra conclusão possível neste momento é do caráter fundante que a ludicidade exerce sobre o jogo, não sendo possível um conceito ou definição de jogo, sem iniciar

\footnotetext{
${ }^{8}$ Minha mãe conta que o irmão dela conhecia 25 regras para esse jogo: "5 marias"; só consegui recuperar 11 delas... certa vez fizemos (nos dizeres de hoje) "viralizar". Por todo lado que olhávamos no pátio da escola, tinha aluno jogando essa brincadeira, com pedrinhas; ou "tarso" outra brincadeira que se espalhou rapidamente entre os alunos (a figurinha de dentro do saquinho de salgadilhos).
} 
pela manifestação lúdica. Por isso, a justificativa de um discurso sobre o lúdico antes de falar do jogo.

Sem preocupação excessiva com conceito fechados, a noção de lúdico que orienta minha prática encontra eco nas ideias do Dr. Cipriano Luckesi (2002), que diferencia atividades lúdicas de ludicidade, a partir da observação de pessoas participantes de ações lúdicas, experimentando e relatando incômodos e até certa agonia, que não podem caracterizar ludicidade. Essa observação levou o autor a concluir que a ludicidade tem mais a ver com "o estado interno do sujeito que praticava e vivenciava a ação" do que com a atividade lúdica, que não pode garantir a ludicidade, apenas convida.

Assim, ao considerarmos a ludicidade como inerente ao ser humano, o jogo, o brinquedo e a brincadeira serão o espaço propício à sua manifestação, para se repensar as atividades dentro da escola. No lugar da pedagogizante: atividade lúdica, a valorização do jogo, do brinquedo e do brincar! Alguns esclarecimentos sobre noções, conceitos e definições de jogos, brinquedos e brincadeiras poderão orientar entendimentos para serem colocados em prática, para garantir a manifestação lúdica.

\section{O Jogo, o Brinquedo e a Brincadeira}

Muitas áreas do conhecimento já exploraram conceitos, definições e práticas do jogo, brinquedo e brincadeira, entre elas: Antropologia, História, Filosofia, Educação, Sociologia, Pedagogia, Psicologia. Dentre os vários autores pesquisados, percebe-se dois grupos distintos, em que um deles trata os três termos com significados separados, considerando o brinquedo como um objeto, a brincadeira como uma ação e o jogo definido pela presença de regras. No outro grupo, os autores não fazem distinção, utilizando as terminologias: jogo, brinquedo e brincadeira sem preocupações específicas, pois, embora elas tenham diferenças seus usos e ações se misturam e se interpenetram. 
Uma das dificuldades de demarcar um limite preciso nos conceitos de brinquedo, como objeto, e brincadeira, como ação está no fato de que, o próprio corpo pode ser o objeto, o brinquedo, portanto confundindo-se com a ação, a brincadeira; outro ponto diz respeito à presença de regras atribuídas somente ao jogo no primeiro grupo e, presente em qualquer brincadeira de acordo com Vigotsky (2009).

No campo da filosofia o jogo está presente no pensamento e tende a se unir a termos como divertimento, alegria, prazer, júbilo. Costumamos compreender o jogo como recreação, como desfrute que rompe com a seriedade e dureza da vida, em suas ocupações diárias. Nesse sentido, o jogo anestesia a crueza e as exigências da vida diária. Lida com a espontaneidade, exige flexibilidade e cria uma atmosfera própria, que só acontece no interior do jogo, quando está sendo jogado, por sua capacidade de transportar o jogador para o campo do imaginário.

Para Huizinga o jogo é:

[...] uma atividade livre, conscientemente tomada como 'não séria' e exterior à vida habitual, mas ao mesmo tempo capaz de absorver o jogador de maneira intensa e total. É uma atividade desligada de todo e qualquer interesse material, com a qual não se pode obter qualquer lucro, praticada dentro de limites espaciais e temporais próprios, segundo uma certa ordem e certas regras. Promove a formação de grupos sociais com tendência a rodearem-se de segredos e a sublinharem sua diferença em relação ao resto do mundo por meio de disfarces ou outros meios semelhantes (1971, p.16).

O jogo faz esquecer por um breve espaço de tempo, a árdua tarefa de existir. É alívio em meio às tensões da vida. Por isso, tomamos o jogo como um verdadeiro instrumento lúdico, pelo estado de ânimo que este pode provocar no jogador. O sujeito joga o jogo em favor de seu divertimento.

Colocando o foco na educação escolar, nosso campo de interesse, trata-se de não deixar essa manifestação ser sufocada, pois, é da natureza humana e da espontaneidade 
natural da pessoa. Quando bem planejado o jogo é muito bem acolhido na escola, pois, ao contrário do que se pensa o jogo é ordem e criar ordem e, a escola perde muito ao considerá-lo como indisciplina e acaba por não conseguir contê-los.

Sabemos que na prática as escolas negam a importância do jogo na educação das pessoas, colocando empecilhos e dificuldades para sua aceitação no ambiente escolar. Entretanto, o próprio PCN estabelece que:

Os jogos podem contribuir com um trabalho de formação de atitudes enfrentar desafios, lançar-se à busca de soluções, desenvolvimento da crítica, da intuição, da criação de estratégias e da possibilidade de alterá-las quando o resultado não é satisfatório - necessárias para a aprendizagem (BRASIL, 1998, p. 47).

Se há esse reconhecimento em um documento que inclui todas as áreas sem distinção, me parece razoável uma possibilidade de jogar o jogo na escola, aprender brincando com atividades que poderão ser lúdicas. Cada área pensa suas possibilidades, com base em seus principais objetivos educacionais, seja para desenvolver determinados conteúdos, ou trabalhar com o universo das linguagens.

Assim, para pensarmos e/ou criarmos um jogo em sala de aula proponho entendê-lo por meio de seus elementos essenciais, ou seja, os traços que definem um jogo, dito de outra forma, os elementos fundantes do jogo, brinquedo ou brincadeira. A ordem das características expostas a seguir representa o pensamento do planejamento do professor, que não é necessariamente fixa, desde que todos os itens sejam observados.

Criando seu próprio jogo, o professor e a turma de alunos pode se desenvolver com autonomia...

As características fundantes do jogo são:

Presença da manifestação lúdica - um dos traços mais definidores do jogo, brinquedo ou brincadeira, segundo Huizinga (1971); a ludicidade é da natureza do 
brinquedo; é propiciadora da criatividade e fruição no jogo. É aqui que conseguimos liberdade para inventar novas estratégias e experiências, para soluções de problemas que por vezes podem ser reais.

Presença de regras - que podem ser alteradas de acordo com a vontade dos participantes; devem ser aceita por todos; esclarecidas antes do início do jogo ou a qualquer momento, quando os próprios jogadores ou o orientador do jogo sentir necessidade; para alguns autores o faz-de-conta é uma regra, própria desse tipo de brincadeira. Ao desobedecer a regra o jogador já está automaticamente fora do jogo, não é preciso puni-lo com a exclusão, ou outro castigo qualquer, quando estamos a favor de uma educação formativa, para a autonomia. A consciência e a motivação interna, são mais importantes.

Limite de tempo e espaço - o jogo é ordem e cria ordem, pois, além das regras serem claras, do que pode e do que não pode ser feito, o limite espaço-temporal está também claro e presente nas regras, mesmo quando não é explícito. O tempo pode ser definido tanto pela conquista do objetivo, que finaliza o jogo, ou pela impossibilidade de sua continuidade, por exemplo, quando a mãe grita: "está na hora de tomar banho", ou outro motivo qualquer. $\mathrm{O}$ espaço deve ser garantido pelas regras, sob pena de impossibilitar as ações do jogador.

Livre escolha - essa característica é um tanto complicada na escola. O professor deve incentivar seu aluno a participar, pois a obrigação faz com que o aluno apenas finja participar, não conseguindo êxito algum, muitas vezes perdendo o caráter lúdico. A livre escolha é uma das garantias da espontaneidade.

Desinteresse pelo resultado - o mais importante é jogar. É claro que durante o jogo o melhor resultado é desejado, mas se isso for imprescindível vira competição, que 
pertence a outro enfoque de discussão, não menos importante, mas que não caba na presente discussão.

Caráter improdutivo - $\mathrm{O}$ aspecto produtivo está relacionado à sociedade de consumo e não à apreensão de conhecimento; se não houver produtividade a maior ênfase é dada ao processo. O resultado do próprio jogo, ou seja, seu produto tem outro significado na escola, diferente e distante do produto e utilidade para ser explorado comercialmente.

Considero ainda, que além das características apresentadas, três focos simultâneos se fazem presentes nesse tipo de atividade, merecendo atenção e reconhecimento: 1) conhecimento - o jogo pode tratar de conteúdo específicos, tanto na forma de compreensão e relações com outros conhecimentos, quanto para memorização; ou seja, o jogo por si só é um lócus de aprendizagem a ser levado em consideração com maior valor; 2) estratégia - didática para o desenvolvimento dos conhecimentos relacionados acima; uma maneira prazerosa de aprender; formas diferentes que podem alcançar todos os alunos de maneiras distintas, explorando os conteúdos do conhecimento, ou as formas de linguagem, e desenvolvendo competências e habilidades nos alunos de ensino básico; e 3) desenvolvimento (alargamento de possibilidades e limites) - formação/construção da autonomia do aluno de desenvolver-se em seus conhecimentos e fazeres para uma edificação de um caminho profissional.

Depois de observados e entendidos esses fundamentos, o próximo passo é criar um objetivo relacionado às expectativas de aprendizagem que se quer dos alunos e ao conteúdo que foi escolhido para ser desenvolvido. Pensar uma dinâmica de funcionamento que seja interessante e exija certo desafio. $\mathrm{O}$ objetivo irá direcionar os resultados esperados. Uma ideia que facilita é a adaptação de jogos populares, 
aproveitando sua essência e dinâmica, adequando regras e funcionamento, direcionando para o conteúdo que se quer ensinar.

\section{Considerações Finais}

O brincar é. Encontra-se no espaço do sonho. Uma criança livre, feliz, brinca quando come, quando sonha, quando faz seus pequenos discursos poéticos. Marina M. Machado

E eu também sou assim, sonhadora, brincalhona, comedora de poesias, histórias, contos e lendas. O brincar é meu maior companheiro em sala de aula, em forma de estratégia, conhecimento e desenvolvimento, e tem me ajudado ao longo desses 30 anos de sala de aula, que esse brincar é uma necessidade humana, que deveria ser mais explorado por todas as áreas do conhecimento.

Essa é sem dúvida uma das limitações deste estudo, pois a fragmentação do mundo moderna a que se submete a academia, dificulta ações que costumam sair do padrão. Fica difícil encontrar pares e referências comuns, pois tudo está separado por área e aqui estamos falando de formação de professor. Me coloco, como alguém que luta pela valorização das possibilidades da manifestação lúdica na escola atual, pelas experiências vivenciadas.

Diante do exposto só resta vivenciar um jogo em sala de aula, ou em algum outro espaço alternativo, para entender como este pode funcionar e mudar a realidade do cotidiano escolar, provocando curiosidade e vontade de aprender nos alunos. Da mesma forma o educador pode criar não só espaços para jogos, mas, adaptar jogos específicos que movimentem os alunos, incitando participação e curiosidades, reflexões e reflexos espontâneos, disponibilidade para o grupo e para a aprendizagem. 
Acredito que sempre é tempo de continuar, transformar, ressignificar e sobretudo aprender com o novo. Por essas razões não posso afirmar que aqui é um ponto final. Prefiro a ideia de uma pausa para a brincadeira. Quem sabe nos encontramos depois para contar se foi bom?

\section{REFERÊNCIAS}

ARIÈS, P. História social da criança e da família. Rio de Janeiro: Zahar, 1982.

BRUNER, E. M. Panorama da Antropologia. São Paulo: Fundo de Cultura, 1963.

BRASIL. Ministério da Educação. Secretaria da Educação Fundamental. Parâmetro curriculares Nacional. $5^{\mathrm{a}}$ à $8^{\mathrm{a}}$ série. Brasília: Mec, 1998.

HUIZINGA, J. Homo Ludens. São Paulo: Perspectiva; Edusp, 1971.

LEONTIEV, A. S. Linguagem, desenvolvimento e aprendizagem. In: LÚRIA, A. R. (Org.) Pensamento e linguagem. São Paulo: Ícone, 1988.

LUCKESI, C.C. Ludicidade e atividades lúdicas: uma abordagem a partir da experiência interna. Ensaios, Salvador, n.2, p. 22-60, 2002. Disponível em: http://luckesi002.blogspot.com.br/2015/08/14-desenvolvimento-dos-estados-de.html Acesso em: 09 fev.2018.

MORAIS, Regis. Filosofia da ciência e da tecnologia: introdução metodológica e crítica. 5. ed. Campinas: Papirus, 1988.

NEGRINE, A. A ludicidade como ciência. In: SANTOS, S. M. P. (Org.) A ludicidade como ciência. Petrópolis: Vozes, 2001.

ORTEGA Y GASSET, J. "Las dos grandes metáforas" In: Obras Completas (OC). Madrid: Tauros, 2004. Tomo II, p. 505-517.

VIGOTSKY, Levi S. Imaginação e criatividade na infância: ensaio psicológico. São Paulo: Editora Ática, 2009.

\section{Endereço da Autora:}

Ângela Barcellos Café

Q. 9 conjunto $C$ casa 41

Sobradinho - DF - 73.035-093

Endereço Eletrônico: abcafe@gmail.com

Endereço Eletrônico: abcafe@gmail.com 